\title{
Aprendizagem Significativa de Conceitos Botânicos em uma Classe de Jovens e Adultos Análise dos Conhecimentos Prévios
}

\author{
Rosalina Evangelista dos Santos ${ }^{1}$ \\ Guadalupe Edilma Licona de Macedo²
}

\begin{abstract}
RESUMO
0 ensino de Ciências visa a favorecer uma maior aproximação dos alunos com as Ciências, permitindo que a população, por meio da aquisição do conhecimento científico e da exploração das novas tecnologias, possa se posicionar diante dos processos e das inovações atuais, defendendo suas opiniões e exercendo a cidadania. Um ensino crítico de Botânica que incorpore os saberes prévios dos discentes tem motivado os professores na construção de alternativas didáticas que possibilitem a ampliação da compreensão dos temas pelos alunos. Este trabalho teve como objetivo analisar o conhecimento prévio dos alunos da EJA acerca de conceitos botânicos, subsidiado pela teoria da Aprendizagem Significativa. 0 estudo foi realizado em uma turma de jovens e adultos do Ensino Fundamental, 2 segmento, em uma escola pública municipal em Encruzilhada - Bahia. A abordagem metodológica foi do tipo qualitativa e como estratégia didática a pesquisa-ação. Para avaliar os conhecimentos prévios dos alunos a estratégia utilizada foi 0 questionário. Os resultados mostraram 0 aluno como agente ativo de sua aprendizagem e o professor como mediador do processo. Os alunos tinham conhecimento botânico baseado no senso comum, visão esta modificada pelo conhecimento científico com a intervenção pedagógica do professor.
\end{abstract}

Palavras-chave: Teoria da aprendizagem. Ensino de Botânica. Educação de Jovens e Adultos.

1 Mestre em Educação Científica e Formação de Professor pela Universidade Estadual do Sudoeste da Bahia. ECFP/Uesb. Docente pela rede estadual de Educação da Bahia. rosallyny @ yahoo.com.br

2 Docente do Programa de Pós-Graduação Educação Científica e Formação de Professor da Universidade Estadual do Sudoeste da Bahia/DCB. gmacedo_3@yahoo.com.br 


\title{
SIGNIFICANT LEARNING OF BOTANICAL CONCEPTS \\ IN A CLASS OF YOUTH AND ADULTS: \\ Analysis of Prior Knowledge
}

\begin{abstract}
The teaching of science aims to promote a closer relationship of students to the sciences, allowing the population, through the acquisition of scientific knowledge and the use of new technologies, can be positioned opposite the processes and current innovations, defending their opinions and exercising citizenship. A critical teaching botany incorporating the prior knowledge of students has motivated teachers in the construction of educational alternatives that enable the expansion of understanding of subjects by students. This study aimed to analyze the prior knowledge of the EJA students about botanical concepts, supported by the theory of Meaningful Learning. The study was conducted in a young adult class of elementary school, II segment in a public school in Encruzilhada- Bahia. The methodological approach was the qualitative type and as a teaching strategy research action. To know the students' prior knowledge the strategy used was the questionnaire. The results showed the student as an active agent of their learning, and the facilitator of the process. Students had a botanical knowledge based in the common sense view, and this view was modified by scientific knowledge with pedagogical intervention by the teacher.
\end{abstract}

Keywords: Learning theory. Botany teaching. Youth and Adult Education. 
Como educadores críticos, precisamos perceber e estimular nossos alunos a reconhecerem a importância das plantas na condição de seres vivos presentes na natureza, não só porque as usamos cotidianamente das mais variadas formas, mas como promotores da vida no planeta, evidenciando entre homem e natureza uma relação de interdependência.

A relação existente entre o homem e o reino vegetal é algo tangível desde épocas muito remotas, seja como remédio, fabricação de utensílios, abrigos, roupas, produtos de beleza, etc. Isto nos leva a crer que a história humana está imbricada à história dos vegetais (OLIVEIRA; SANTOS; MACHADO; GUIMARÃES; CARNEIRO, 2013). Daí a importância de estudá-los, a fim de compreender seus mecanismos internos de reprodução, desenvolvimento, adaptação, etc., suas características morfológicas, além de se pretender uma otimização do uso desses materiais orgânicos no cotidiano.

Nesse sentido, é sabido que, quando se estabelece uma relação entre saberes do senso comum, aquele que o aprendiz traz consigo advindo de suas experiências cotidianas, e o saber científico, há uma maior possibilidade de ocorrência da aprendizagem significativa (VEIGA JÚNIOR; PINTO; MACIEL, 2005). Isso permitirá ao discente, com a ajuda do professor, que será o mediador, questionar, confrontar, analisar, concluir, inferir e aprender, partindo da sua prática cotidiana, permitindo-lhe uma Aprendizagem Significativa.

Aprendizagem Significativa é aquela definida como um processo por meio do qual nova informação relaciona-se, de maneira não linear e não imposta, a um aspecto relevante da estrutura de conhecimento do indivíduo. Isto é, um conhecimento que tenha um sentido para a sua vida prática cotidiana, considerando-se os seus conhecimentos prévios, que servirão como ancoradouro para o novo conhecimento (AUSUBEL, 2000; MOREIRA, 2011). Esse processo de interação é chamado de ancoragem (AUSUBEL, 1968).

De acordo com os PCNs (BRASIL, 1999), são objetivos do ensino de Ciências o desenvolvimento da prática de forma contextualizada, vinculada às necessidades cotidianas, possibilitando o desenvolvimento acerca dos conhecimentos relacionados à cultura, porém de forma ampliada. 
No que respeita ao ensino de Ciências na EJA, há que se destacar alguns avanços: a educação para os jovens e adultos já não visa mais à alfabetização para formação de mão de obra mais bem qualificada, visa a formar o cidadão trabalhador, como proposto na LDB - Lei de Diretrizes e Bases (BRASIL, 1996). Além disso, de acordo com Vilanova e Martins (2008), a tendência das últimas décadas dessa modalidade de ensino tem sido buscar se configurar como um campo pedagógico comprometido com o desenvolvimento de reflexões críticas sobre suas necessidades e objetivos, incluindo aí ensinar a partir das necessidades dos aprendizes, utilizando seus conhecimentos prévios, para uma aprendizagem significativa, tendo como ponto de partida o meio em que vivem, possibilitando o intercâmbio de informações.

A Educação de Jovens e Adultos teve sua gênese no Brasil na época do Império, quando foram elaboradas várias reformas educacionais que preconizaram a necessidade de haver classes noturnas de ensino elementar para adultos analfabetos. Essa iniciativa resultou em 200 mil alunos frequentando as aulas de ensino elementar.

Em 1940, diante dos altos índices de analfabetismo no país, a educação de adultos passou a ter importância, e foi criado um fundo destinado à alfabetização de adultos analfabetos. Em 1945 surgiu um movimento de fortalecimento dos princípios democráticos, e a Organização das Nações Unidas para a Educação, a Ciência e a Cultura (Unesco) foi criada. A partir daí os países integrantes do órgão são conclamados a buscar meios para educar a população adulta analfabeta. A Lei de Diretrizes e Bases (LDB, p. 65) 9394/96 estabeleceu princípios básicos para a EJA:

[...] igualdade de condições para o acesso de permanência na escola; [...] pluralismo de ideias e de concepções pedagógicas; [...] garantia de padrão de qualidade; [...] valorização da experiência extraescolar; [...] vinculação entre a educação escolar, o trabalho e as práticas sociais. 
De lá para cá o ensino da EJA evoluiu e a legislação atual garante o ensino para jovens e adultos, considerando suas especificidades, necessidades, esperanças em relação à vida, sua identidade e inserção no mundo do trabalho. Os atuais desafios da Educação de Jovens e Adultos são elevar o padrão de qualidade do ensino e alcançar o maior número possível de jovens e adultos.

A EJA oferece oportunidade para pessoas que estão fora da faixa etária escolar voltarem a estudar e completar sua formação. O ensino tradicional, baseado na transmissão de informações que são memorizadas e cobradas em avaliações pontuais e classificatórias, tipo de ensino consolidado há muitas décadas, não tem alcançado resultados satisfatórios.

Em se tratando especificamente do ensino de Botânica, percebemos que este é pautado nas aulas expositivas com o professor como figura central da aprendizagem, o qual ministra aulas lineares e descontextualizadas da realidade do aluno. Assim, o aprendiz fica na condição de espectador passivo e não estabelece relação entre os conteúdos aprendidos na escola e a realidade. As aulas práticas, na maioria das vezes, ficam de fora, e, dessa forma, torna-se difícil compreender aspectos associados à estrutura e fisiologia das plantas.

No intuito de alavancar a qualidade da educação, teorias que valorizam o sujeito aprendiz como agente ativo de sua aprendizagem trouxeram novas perspectivas e esperanças para o ensino. Tais teorias são denominadas construtivistas, por motivarem o estudante a construir seu conhecimento a partir de sua experiência, ativando seus conhecimentos prévios e agregando os saberes escolares com a mediação do professor, cujo desempenho para a promoção da aprendizagem significativa só será validado a partir do reconhecimento da importância do seu papel social.

O aprendizado precisa ser significativo para que seja consolidado. A teoria de Ausubel enquadra-se no rol das teorias construtivistas e propõe a aprendizagem significativa. Esta foi formulada na década de 60, mas continua atual e pode ser incorporada na prática pedagógica dos diferentes níveis de ensino, principalmente na Educação de Jovens e Adultos. 
De acordo com as ideias de Ausubel, Novak e Hanesian (1980), o aluno é considerado como sujeito de sua aprendizagem na medida em que os conhecimentos que ele traz de sua vida, de suas experiências e vivências são ponto de partida para a aquisição de novos conhecimentos.

\section{O Ensino de Ciências: a Botânica no Cotidiano das Pessoas}

O ensino de Ciências é discutido pelos PCNs (BRASIL, 1999), direcionando-os não apenas para a preparação do discente para o ingresso na faculdade, mas visando a dar a ele lições de cidadania e conhecimento crítico-científico, histórico-social, filosófico, possibilitando a sua inserção no mundo do trabalho. Na visão de Costa (2011), ele visa a favorecer uma maior aproximação dos alunos com as Ciências, permitindo que a população, por meio da aquisição do conhecimento científico e da exploração das novas tecnologias, possa se posicionar diante dos processos e das inovações atuais, defendendo suas opiniões e exercendo a cidadania. Por isso há, de forma muito presente, uma necessidade de compreendê-lo e aceitá-lo como instrumentalizador intelectual, necessário para que o indivíduo se desenvolva e que, de forma crítica, seja capaz de fazer escolhas, mediante circunstâncias diversificadas que lhe forem apresentadas, e muitas vezes impostas, pela sociedade, que tem se tornado cada vez mais excludente.

De acordo com os PCNs (BRASIL, 1999), são objetivos do ensino de Ciências o desenvolvimento da prática de forma contextualizada, relacionada às necessidades cotidianas, possibilitando o desenvolvimento acerca dos conhecimentos ligados à cultura, porém de forma ampliada.

A preocupação pela busca de um ensino crítico de Botânica, que incorpore os saberes prévios dos discentes, sem com isso desprezar os aspectos teóricos da área, tem motivado os professores na elaboração de alternativas didáticas que possibilitem a ampliação da compreensão dos temas pelos discentes. A redescoberta e utilização de metodologias como o uso de cartilhas - história de 
planta e gente, passeios nos jardins, aula prática no laboratório, organização de jardim botânico na escola e oficinas de aprendizagem - podem ilustrar experiências bem-sucedidas de ensino (GÜLLICH, 2006).

$\mathrm{O}$ ensino sobre as plantas é muitas vezes realizado sem referências à vida do aluno, mesmo elas fazendo parte do seu cotidiano. Dessa forma, o que é ensinado na escola, embora haja possibilidade de se fazer relação por meio de exemplos na rua na qual o aluno passa cotidianamente ou mora, dificilmente será percebido por ele. No caso aqui específico, o campo é o lugar de trabalho dos alunos, pois são trabalhadores e moradores do campo e lidam diretamente com as plantas. Por isso é importante a aplicação de uma metodologia que estimule as vinculações entre senso comum e científico.

Pensar o processo de ensino em uma perspectiva de aprendizagem significativa é empreender esforços para trazer ao contexto da sala de aula as concepções espontâneas dos alunos, uma vez que a ancoragem dos conhecimentos que deverão ser agregados só será possível partindo dos conhecimentos prévios. Segundo Ausubel , Novak e Hanesian (1980), a nova informação baseia-se nos conhecimentos que o sujeito já possui, modificando o conhecimento já adquirido, o qual passa a fazer parte da estrutura cognitiva, isso é chamado de ancoragem. E o conhecimento que o aprendiz já traz como experiência é denominado subsunçor. ${ }^{3}$ Nesse sentido, para Ausubel (2000), o conhecimento prévio é a variável, mas importante e essencial para a ocorrência da aprendizagem significativa .

Promover o ensino com essas características em classes de EJA é ver aí possibilidades de construção de conhecimento, abdicando de práticas memorísticas e descontextualizadas. "Tornar os jovens e adultos mais críticos e conscientes de sua realidade é uma necessidade, não abandonando, porém, as questões conceituais que as disciplinas fornecem para auxiliar no entendimento das situações e fenômenos observados (GOMES; GARCIA, 2014, p. 297).

3 O "subsunçor" é um conceito, uma ideia, uma proposição já existente na estrutura cognitiva, capaz de servir de "ancoradouro" a uma nova informação, de modo que esta adquira, assim, significado para o indivíduo (isto é, que ele tenha condição de atribuir significados a essa informação) (MOREIRA, 2006, p. 15).

A palavra "subsunçor" não existe em português, trata-se de uma tentativa de traduzir a palavra inglesa "subsumer" (MOREIRA, 2006, p. 15). 


\section{Metodologia}

Este trabalho faz parte de uma pesquisa de Mestrado, na qual investigamos os conhecimentos prévios que os alunos de uma classe de jovens e adultos tinham sobre a Botânica.

O conhecimento sobre um determinado objeto permitirá entender sua origem, aparência, função, significado, sua relação com outros objetos, etc. De um mesmo objeto pode-se obter um conhecimento horizontal, mais superficial, e um conhecimento vertical, mais profundo, investigar além da aparência simples do objeto, até as implicações de seu relacionamento com outras estruturas da própria realidade.

Neste sentido, para se alcançar o objetivo proposto, inicialmente foi realizado um diagnóstico por meio de um questionário a fim de identificar os conhecimentos prévios que serviriam como âncora, presentes na estrutura cognitiva dos estudantes. De acordo com a teoria da aprendizagem significativa, um dos passos a serem dados é a diferenciação progressiva que consiste no princípio segundo o qual os conteúdos devem ser apresentados sempre a partir dos conceitos/ideias mais amplos para os mais particulares (AUSUBEL; NOVAK; HANESIAN, 1980). Desta forma, o professor seleciona os itens curriculares relevantes e deve sequenciá-los de modo que os mais gerais sejam trabalhados antes dos mais específicos, pois servirão como subsunçores. Subsunçor é um conceito, uma ideia, uma proposição já existente na estrutura cognitiva do aprendiz que serve de "ancoradouro", para o novo conhecimento, permitindo ao indivíduo atribuir-lhe significado (AUSUBEL; NOVAK; HANESIAN, 1980). Nesse caso, vegetal é o termo mais abrangente e planta o mais específico.

A aplicação da proposta deu-se no decorrer da Unidade 2 em uma turma de jovens e adultos do Ensino Fundamental, $2^{\circ}$ segmento, de uma escola pública municipal em Encruzilhada - Bahia, no período compreendido entre maio e agosto de 2015. A pesquisa que realizamos foi de natureza qualitativa. Segundo Bardin (2009, p. 141), "é um tipo de pesquisa válida, sobretudo, na elaboração das deduções específicas sobre um acontecimento ou uma variável de inferência precisa, e não em inferências gerais". O qualitativo "engloba a ideia 
do subjetivo, passível de expor sensações e opiniões" (BICUDO, 2006, p. 106). Envolve também percepções de diferenças e semelhanças, não sendo aplicável a ele a noção de rigorosidade, pois aos dados faltam precisão e objetividade.

Moreira (2011) corrobora destacando que a metodologia qualitativa tem pressupostos que envolvem a realidade socialmente construída e objetiva, a compreensão do fenômeno social, de acordo com as perspectivas dos atores sociais, e com foco em significados e experiências, procurando explicação interpretativa dos fatos.

Assim, o papel do pesquisador é realizar anotações, ouvir, observar, registrar, documentar, buscar significados, interpretar de maneira persuasiva, descritiva e detalhada, por meio de uma linguagem acessível e com detalhes suficientes para evidenciar a aproximação dos dados obtidos com a realidade dos atores (MOREIRA, 2011).

\section{Resultados e Discussão}

Tomando como ponto de partida o fato de todos, de alguma forma, terem conhecimento sobre o uso das plantas como remédio, alimento, vestuário, entre outras aplicações, o encontro iniciou-se com a apresentação da proposta do trabalho. Em seguida foi aplicado o questionário.

As Orientações Curriculares para o Ensino Fundamental e Médio apontam que as atividades práticas dinâmicas ou experimentais não garantem a produção de conhecimentos significativos, mas é uma importante ferramenta para a sua construção.

Sabemos que vários fatores precisam ser considerados na elaboração de uma proposta do ensino na EJA para possibilitar a escolarização de pessoas que estão fora da faixa etária e aqueles que, por diversos motivos, estão longe da escola há algum tempo. Nesse sentido, a metodologia de ensino deve apreciar uma dinâmica diferenciada que envolva os alunos em questões relacionadas ao seu cotidiano e resultando na vida prática (PICONEZ, 2006). 
É possível que tenha ocorrido, nessa situação pedagógica, aprendizagem significativa, a qual acontece quando a nova ideia se relaciona de forma não arbitrária e lógica numa combinação de conteúdos inter-relacionados e relevantes. Não foi uma aprendizagem mecânica sem associação a conceitos relevantes presentes na estrutura cognitiva. O uso das plantas faz parte da cultura dos alunos e, conciliando com as informações de caráter científico, amplia-se o conhecimento de mundo e científico dos alunos.

Nesse sentido, os conceitos ou ideias existentes na estrutura cognitiva do indivíduo podem servir como ancora à nova informação de tal forma que ela adquira significado para o indivíduo, a isso Ausubel dá o nome de ancoragem (AUSUBEL; NOVAK; HANESIAN, 1980).

As análises das concepções prévias dos alunos sobre os conceitos de Botânica, obtidos no questionário inicial, foram organizados nas tabelas a seguir, formando categorias de conceitos de acordo com as quantidades em que ele é mencionado nas respostas, seja de forma direta ou indireta. Na sequência a transcrição das falas de alguns alunos acerca do questionamento.

Tabela 1 - Quantitativo por categoria "O que é planta"

\begin{tabular}{cc}
\hline \hline Respostas & Número de alunos \\
\hline Ser vivo & 10 \\
Vegetal & 4 \\
Maravilha da natureza & 1 \\
Não responderam & 5 \\
\hline \hline
\end{tabular}

Fonte: Pesquisa de campo, 2015.

A seguir algumas respostas dos estudantes ${ }^{4}$ ao primeiro questionamento, sobre a definição de plantas.

QA1 - "É um ser vivo muito importante para nós, pois ela faz a fotossíntese, que é o gás oxigênio".

QA6 - "Um vegetal que se alimenta da luz solar"

QA3 - "É um ser vivo que também faz parte do planeta".

${ }_{4}$ As respostas dadas pelos participantes da pesquisa serão representadas por letras e números da seguinte forma QA1, QA2..., em que a letra Q representa o questionário, a letra A acompanhada do numeral, o participante. 
As respostas revelam uma concepção correta do termo planta. O conceito, o significado atribuído à planta, é socialmente respaldado, uma vez que claramente foi adquirido em outro momento da vida escolar desses alunos. $\mathrm{O}$ vocábulo planta faz parte do vocabulário dos alunos em sua vida cotidiana, no entanto o conceito científico atribuído por eles é fruto da escolarização. Houve, nesse caso, uma "retenção significativa" (AUSUBEL, 2000, p. 3).

Embora a maioria conceba as plantas como um ser vivo, no início da pesquisa um número considerável não soube definir "planta", o que caracteriza a deficiência no ensino de Ciências em séries anteriores para esses alunos, pois as plantas são conteúdos que, de acordo com a matriz curricular, devem ser ministrados no $4^{\circ}$ e $7^{\circ}$ anos do Ensino Fundamental, ainda que seja em classes de EJA. Este inclusive foi um dos critérios de inclusão utilizado para a escolha da turma. Além disso, as plantas fazem parte do cotidiano dos alunos da EJA, uma vez que estes são, em sua maioria, trabalhadores do campo.

As falhas no ensino de Ciências podem ser explicadas pelo modelo de ensino praticado baseado na figura do professor como detentor do conhecimento, com aulas expositivas, lineares e descontextualizadas, que não estimulam os alunos a construírem novos conhecimentos (BIZZO, 2001; KRASILCHIK, 2011). A aula expositiva favorece a memorização porque oferece conceitos prontos e abstratos, distantes da realidade do aluno, e, por esta razão, o que foi memorizado logo é esquecido.

Na concepção de Bizzo (2001), no entanto, os alunos não responderam erroneamente à primeira questão, mas deram respostas vazias e incompletas no que se refere ao conceito de planta, e também não justificaram por meio de características o que seria um vegetal.

A linguagem é considerada uma importante facilitadora da aprendizagem significativa. $O$ poder representacional das palavras facilita a manipulação de conceitos e proposições. Sendo a maioria dos alunos advinda da zona rural e trabalhadores do campo, conhecem variadas espécies de plantas. Conceitos mais relevantes e inclusivos interagem com o novo material, abrangendo e integrando este conteúdo e ao mesmo tempo modificando-o. A concepção que os alunos tinham de planta, trazida do seu dia a dia, a qual fazia parte de seu repertório 
pessoal (conhecimentos prévios), representa conceitos importantes e inclusivos, e tal concepção foi transformada pela intervenção do professor em aulas anteriores, promovendo integração do que já conheciam com as informações novas fornecidas pela escola.

A seguir algumas respostas apresentadas pelos alunos à segunda questão do questionário inicial, a qual indagava sobre a sua concepção conceitual sobre planta e vegetal:

QA2 - "Usamos vários tipos de vegetal em nosso dia a dia e as plantas também".

QA3 - "Falamos de vegetal quando se fala de alimento".

QA4 - "Porque vegetal a gente come e planta não".

QA18 - "A planta também é uma vegetação".

Ao verificar as respostas para a segunda pergunta, foi possível perceber que a grande maioria dos discentes percebe plantas e vegetais como sinônimos, porém para alguns o termo vegetal só é aplicado às plantas que são usadas como alimento. "Plantas nós não comemos e vegetal sim" (QA5).

Para os discentes, não há diferença na forma como eles representam plantas e vegetais. Essa forma de entender os dois conceitos pode estar relacionada a visões equivocadas, advindas do meio em que estão inseridos; isto é, de acordo com as suas concepções alternativas, intuitivas ou espontâneas (MERHY; SANTOS, 2014; JUDD ; CAMPBELL; KELLOGG; STEVENS; DONOGHUE, 2002).

O termo planta ou vegetal é definido por diversas pessoas como um ser vivo verde que não se movimenta (JUDD; CAMPBELL; KELLOGG; STEVENS; DONOGHUE, 2002). Pesquisadores e estudiosos do assunto, porém, incluem entre os vegetais os fungos, que são seres aclorofilados e que são estudados por micologistas, além das plantas. Estas são caracterizadas como organismos que possuem características específicas, tais como: fotossíntese, presença de parede protetora celulósica, esporos e imobilidade (JUDD;CAMPBELL; KELLOGG; STEVENS; DONOGHUE, 2002). 
Como citado anteriormente, os conteúdos devem ser apresentados sempre a partir dos conceitos/ideias mais amplos para os mais particulares (AUSUBEL; NOVAK; HANESIAN, 1980). Nesse caso, vegetal é o termo mais abrangente e planta o mais específico.

Segundo Ausubel, Novak e Hanesian (1980), a partir daí ocorre a hierarquização de conceitos. Este tipo de hierarquia é a que acontece na mente de cada pessoa: as ideias mais gerais/inclusivas ocupam o topo da estrutura cognitiva e têm subordinadas a si ideias progressivamente mais específicas/menos inclusivas. Para os alunos, essa hierarquização manifestou-se de maneira confusa, surgindo a necessidade de trabalhar um organizador prévio que movimentasse as estruturas cognitivas dos alunos e promovesse a reconciliação integrativa e, consequentemente, a diferenciação progressiva de maneira a tornar os dois conceitos mais claros e definidos para os discentes.

Na Tabela 2 apresentamos as concepções dos alunos sobre o termo Botânica e o lugar onde eles haviam escutado.

Tabela 2 - Quantitativo por categoria de "Onde ouviu falar do termo Botânica"

\begin{tabular}{cc}
\hline \hline Respostas & Número de alunos \\
TV & 1 \\
Escola & 2 \\
Não me lembro & 4 \\
Não responderam & 13 \\
\hline \hline
\end{tabular}

Fonte: Pesquisa de campo, 2015.

Ao analisarmos as respostas para esta questão percebemos que o termo Botânica não faz parte do repertório de conhecimento dos alunos, pois 17 deles disseram não ter conhecimento sobre e somente 3 afirmaram já ter ouvido falar. O estudo sobre Botânica faz parte do ensino de Ciências, geralmente no $7^{\circ}$ ano do Ensino Fundamental e no $2^{\circ}$ ano do Ensino Médio. Embora existam muitas fontes de informação como televisão, revistas, jornais, livros didáticos, o termo 
Botânica ainda é pouco conhecido pelos alunos, embora tenha relação com as plantas e, sobretudo, com o ensino de Ciências (BITENCOURT; MACEDO, 2008).

Como citado anteriormente pelos discentes, as plantas têm importante papel na vida do homem, pois servem de alimento, remédio, ornamentação. Isso revela que, por ter grande importância para o planeta Terra, o ensino de Botânica precisa ser incrementado, podendo até ser motivador para o ensino de Ciências na EJA.

Segundo Silva e Cavassan (2006), o ensino de Ciências precisa ser ministrado de maneira interessante, explorando conteúdos de forma que o aluno se sinta motivado a questionar, buscando a coletânea de seus saberes práticos, suas vivências, sem deixar de conscientizá-lo acerca dos bens naturais. Para Oliveira et al. (2013), uma boa forma de ensinar sobre as plantas é promovendo um contato entre o discente e elas, pois assim o aluno sentir-se-á sensibilizado e será capaz de fazer a correlação com o ambiente no qual está inserido (BIZZO, 2001).

Segundo Cicillini (2002), Arruda e Laburú (1996) e Ceccantini (2006), normalmente são ministradas aulas para ensinar sobre as plantas, e não se faz uso de metodologias que busquem a promoção de um maior contato entre discentes e vegetais, de forma a tornar a aula mais participativa. Esse fato tem levado tanto o aluno quanto o professor a desenvolverem uma relação apática acerca do ensino-aprendizagem de Botânica sobre a temática.

Ao se indagar sobre a importância das plantas, foram obtidas as respostas representadas na Tabela 3 .

Tabela 3 - Quantitativo por categoria "A importância da planta na vida cotidiana"

\begin{tabular}{cc}
\hline Respostas & Número de alunos \\
Processos vitais & 10 \\
Uso medicinal & 4 \\
Afetividade & 4 \\
Nenhuma & 2 \\
\hline
\end{tabular}

Fonte: Pesquisa de campo, 2015. 
A seguir algumas das respostas dos participantes:

QIA1 - "Por que sem ela a gente não pode ter ar".

QIA6 - "Tudo, pois hoje em dia nós vivemos em função das plantas".

QIA8 - "São meios onde são usados para a medicina e uso caseiro".

QIA9 - "A planta é muito importante no meu dia a dia, todos os dias eu levanto e cuido delas, para mim é importante".

Ao fazer este questionamento buscamos averiguar se os alunos percebiam as plantas para além das necessidades humanas, compreendendo-as como fundamentais para a manutenção da vida no planeta, pois as plantas estão na base das cadeias alimentares. Percebeu-se que a maioria vê as plantas apenas fazendo parte de processos vitais, como nutrição e respiração, devido à produção de oxigênio por elas, o que não deixa de ser verdade. Bizzo (2001), no entanto, revela ser esta uma visão utilitarista antropocêntrica que as pessoas têm das plantas. Embora timidamente, alguns alunos reconheceram as plantas como mantenedoras da vida no planeta, quando afirmam, por exemplo, que "Vivemos

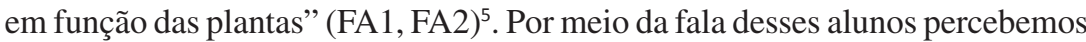
que eles veem as plantas como seres vivos importantes nos ecossistemas, sem os quais não poderia haver vida.

A atribuição de sentido e significado às plantas requer que o aluno seja exposto a uma "situação contextual inclusiva" (AUSUBEL, 2000). Para isso, o professor pode fazer uso de ilustrações, imagens e fotografias, recursos que envolvam situações associadas ao conteúdo desenvolvido e constituem-se em instrumentos que podem gerar reflexões e auxiliar o processo de construção do conhecimento, ampliando o conteúdo abordado. É importante que o educador oriente os alunos a não só observar a imagem em si, mas sobretudo a ler as legendas que a acompanham.

5 As respostas dadas pelos participantes da pesquisa serão representadas por letras e números da seguinte forma: FA1, FA2..., em que a letra F representa a fala, a letra A acompanhada do numeral, o participante. 
De acordo com o interesse dos alunos, o professor poderá utilizar as imagens para aprofundar um assunto sugerindo e orientando outras atividades, como pesquisas, leituras de textos e interação com outras disciplinas.

A construção do sentido é subjetiva, fruto da relação que fazemos com repertório particular. A partir de uma situação contextual inclusiva, o aluno pode atribuir sentido e depois significado à função das plantas. O significado que os alunos deram às plantas como seres vivos fundamentais ao ecossistema é uma construção social, conhecimento compartilhado por muitas pessoas e que tem aprovação social.

Quando indagados acerca do processo reprodutivo das plantas, percebemos que os alunos pouco conhecem sobre este assunto, pois, dos 20 alunos interrogados, 15 não responderam, como mostrado na Tabela a seguir.

Tabela 4 - Resposta sobre "A reprodução das plantas"

\begin{tabular}{cc}
\hline Respostas & Número de alunos \\
Polinização & 3 \\
Semente & 2 \\
Não responderam & 15 \\
\hline
\end{tabular}

Fonte: Pesquisa de campo, 2015.

Transcrição de algumas respostas apresentadas pelos alunos para esta questão:

QA1 - "A reprodução ocorre por causa dos insetos"

QA2 - "E pela semente, pois agente planta uma semente quando quer fazer uma muda."

Por meio das respostas apresentadas para esta questão constatamos que apenas alguns dos alunos associaram a reprodução das plantas à polinização e sementes. Fica evidente o pouco conhecimento por parte dos aprendizes sobre os processos reprodutivos desses seres vivos, tomando como embasamento o fato de que a maioria deles não respondeu à indagação. 
Três alunos responderam que as plantas se reproduzem por meio da polinização. Este se constitui um fato verdadeiro, porém isso se aplica somente às plantas superiores. Embora uma minoria tenha dado essa resposta, ficou evidente a falta de conhecimento dos alunos sobre o mecanismo de reprodução vegetal: reprodução sexuada e assexuada (RAVEN; EVERT; EICHHORN, 2007). No caso da polinização, ocorre por meio sexuado.

O conhecimento acumulado é retido na memória de longo alcance e acessado quando necessário. Fica claro pelas respostas dadas que os alunos não tinham armazenado na memória o modo de reprodução assexuada das plantas. Eles demonstraram possuir os conhecimentos prévios, os subsunçores que serviram de ancoradouro, para o conteúdo reprodução sexuada das plantas. A reprodução sexuada é análoga à dos humanos, portanto mais próxima da realidade do aluno, uma vez que o pólen pode ser comparado ao espermatozoide, e a planta possui ovário para receber o pólen quando da fecundação. A reprodução assexuada, ao contrário, não faz parte do repertório cognitivo presente na memória de longo alcance dos alunos. É um conteúdo abstrato, com o qual os alunos não conseguem fazer analogia; por isso não ocorreu a aprendizagem proposicional, pois ela necessita de conhecimento prévio dos conceitos e símbolos. Seu objetivo é promover uma compreensão sobre uma proposição por meio da soma de conceitos mais ou menos abstratos.

Sabemos que desde a época que o homem era caçador-coletor, as plantas já eram utilizadas para diversos fins, incluindo a alimentação. Com o aparecimento do hábito sedentário, o homem passou a domesticar animais e plantas, desenvolvendo a agricultura. Desde então as plantas têm desempenhado um importante papel no nosso dia a dia no que se refere à obtenção dos nutrientes para uma vida saudável (MACIEL; PINTO; VEIGA-JUNIOR, 2002).

Nesse sentido, o conhecimento das necessidades nutricionais do organismo, da composição dos principais alimentos que fazem parte da nossa dieta e das suas propriedades nutricionais deve fazer parte da formação cultural do cidadão. 


\section{Considerações Finais}

O ensino de Botânica, alicerçado na memorização de conceitos sem aplicações práticas, resulta numa aprendizagem mecanicista ineficiente. Por outro lado, o ensino de Botânica voltado para o desenvolvimento de competências e habilidades que permitam ao aluno absorver informações, compreendê-las, reelaborá-las e utilizá-las na vida e no seu trabalho, aprofunda e consolida o aprendizado.

Os alunos da EJA são especialmente dotados de experiências por terem mais idade e por precocemente terem entrado no mercado de trabalho. A volta ao meio escolar representa um grande passo e elevação da autoestima desses sujeitos.

A aplicação da teoria de Ausubel nas aulas de Botânica pode auxiliar o aluno a dar significado a conceitos científicos, formular questões, diagnosticar e propor soluções para problemas reais com base em elementos da Botânica, colocando em prática conceitos, procedimentos e atitudes desenvolvidos na constituição do conhecimento.

A aprendizagem significativa considera o aluno um agente ativo de sua aprendizagem, e o professor age como mediador do processo. As experiências vivenciadas pelo aluno são levadas em consideração e, assim, ele é libertado da categoria de assistente passivo, que não opina e apenas absorve o que lhe é ensinado, estabelecendo relação entre o que aprende na escola e a sua vida (seu corpo, seu cotidiano, as práticas políticas, culturais, e de comunicação da sociedade em que vive, etc.).

\section{Referências}

ARRUDA, S. M.; LABURÚ, C. E. Considerações sobre a função do experimento no ensino de Ciências. Pesquisa em Ensino de Ciências e Matemática, São Paulo, n. 5, p. 14-24, 1996.

AUSUBEL, D. P. The acquisition and retention of knowledge: a cognitive. View. Dordrecht: Kluwer Academic Publishers, 2000. 
AUSUBEL, D. P., NOVAK, J. D., HANESIAN, H. Psicologia educacional. Tradução Eva Nick. Rio de Janeiro: Interamericana, 1980.

.Educational psychology: a cognitive view. Nova York: Holt; Rinehart; Winston. 1968.

BARDIN, L. Análise de conteúdo. Tradução Luís A. Reto e Augusto Pinheiro. 5. ed. Lisboa: Edições 70, 2009.

BICUDO, M. A. V. Pesquisa em educação matemática. Proposições, Campinas, v. 4, n. 10, p. 18-23, 2006.

BITENCOURT, I. M. A.; MACEDO, G. E. L. As plantas na percepção dos alunos do Ensino Fundamental no município de Jequié - BA. 2008. Monografia (Graduação) UESB, Jequié, 2008.

BIZZO, N. Ciências: fácil ou difícil? São Paulo: Ática, 2001.

BRASIL. Ministério da Educação. Secretaria de Educação Fundamental. Parâmetros Curriculares Nacionais: ciências naturais. Brasília: MEC; SEF, 1999.

. Ministério da Educação. Lei de Diretrizes e Bases da Educação Nacional $n^{o}$ 9394/96. Brasília, 20 dez. 1996.

CECCANTINI, G. Os tecidos vegetais têm três dimensões. Revista Brasileira Botânica, São Paulo, v. 29, n. 2, p. 335-337, 2006.

CICILLINI, G. A. Conhecimento científico e conhecimento escolar: aproximações e distanciamentos. In: CICILLINI, Graça A.; NOGUEIRA, Sandra V. (Org.). Educação escolar: políticas, saberes e práticas pedagógicas. Uberlândia: Edufu, 2002. p. 37-66.

COSTA, E. A. Gestão estratégica, da empresa que temos para a empresa que queremos. 2. ed. São Paulo: Saraiva, 2011. 424p.

GOMES, A. T.; GARCIA, I. K. Aprendizagem significativa na EJA: uma análise da evolução conceitual a partir de uma intervenção didática com a temática energia. In: Investigações em Ensino de Ciências, Educação em Ciências PPG Educação em Ciências. Química da Vida e Saúde, UFSM, Santa Maria, v. 19(2), p. 289-321, 2014.

GÜLLICH, R. I. C. As práticas de ensino de Botânica e a SBB. In: MARIATH, J. E. A.; SANTOS, R. P. Os avanços da botânica no início do século XXI. Porto Alegre: Imagine 2006. p. 695-699.

JUDD, W. S. et al. Plant systematic: a plylogenetic approach. Second edition. Sunderland, MA: Sinauer associates, Inc., 2002.

KRASILCHIK, M. Prática de ensino de biologia. São Paulo: Ed. da Universidade de São Paulo, 2011. 
MACIEL, M. A. M.; PINTO, A. C.; VEIGA-JUNIOR, V. F. Plantas medicinais: a necessidade de estudos multidisciplinares. Química Nova, v. 25, n. 3, p. 429-438, 2002.

MERHY. T. S. M.; SANTOS. M. G. Planta ou vegetal? As concepções alternativas dos alunos do Ensino Fundamental. In: Experiências em Ensino de Ciências, v. 9, n. 2, 2014.

MOREIRA, M. A. Aprendizagem significativa subversiva. Campo Grande: UCDB, 2011. p. 15-32. (Série Estudos - periódico do Mestrado em Educação da UCDB, n. 21).

MOREIRA, M. A. A teoria da aprendizagem significativa e sua implementação em sala de aula. Brasília: Editora Universidade de Brasília, 2006.

OLIVEIRA, W. M. et al. Estudo de caso sobre abordagem de aspectos sociocientíficos em aulas de ciências naturais do Ensino Fundamental. In: REUNIÃO ANUAL DA SBPC, 61. 2009, Manaus. Jornada Nacional de Iniciação Científica, Manaus, 2013.

PICONEZ, S.C. B. Educação escolar de jovens e adultos: das competências sociais dos conteúdos aos desafios da cidadania. 5 ed. Campinas: Papirus, 2006.

RAVEN, P. H., EVERT, R. F.; EICHHORN, S. E. 2007. Biologia vegetal. 7. ed. Coord. E trad. J. E. Kraus. Rio de Janeiro: Ed. Guanabara Koogan, 2007.

SILVA, P. G. P.; CAVASSAN, O. Avaliação das aulas práticas de Botânica em ecossistemas naturais considerando-se os desenhos dos alunos e os aspectos morfológicos e cognitivos envolvidos. Revista Ciências Humanas (Mimesis), Bauru, v. 27, n. 2, p. 33-46, 2006.

VEIGA JUNIOR, V. F.; PINTO, A. C.; MACIEL, M. A. M. Plantas medicinais: cura segura? Química Nova, v. 28, n. 3, p. 519-528, 2005.

VILANOVA, R.; MARTINS, I. Educação em Ciências e Educação de Jovens e Adultos: pela necessidade do diálogo entre campos e práticas. Ciência \& Educação, v. 14, n. 2, p. 331-346, 2008.

Recebido em: 18/8/2016

Aceito em: 11/10/2016 